\title{
The effect of an exercise program on communication and behavior of a child with Autism Spectrum Disorder
}

\author{
Stavrou K. ${ }^{1 \mathrm{ABC}}$, Tsimaras V. ${ }^{2 \mathrm{AD}}$, Alevriadou A. ${ }^{1 \mathrm{AE}}$, Gregoriadis A. ${ }^{3 \mathrm{~A}}$ \\ ${ }^{1}$ School of Early Childhood Education, University of Western Macedonia, Greece \\ ${ }^{2}$ School of Physical Education and Sport Science, Aristotle University of Thessaloniki, Greece \\ ${ }^{3}$ School of Early Childhood Education, Aristotle University of Thessaloniki, Greece
}

Authors' Contribution: A - Study design; B - Data collection; C - Statistical analysis; D - Manuscript Preparation; E - Funds Collection.

\begin{tabular}{|c|c|}
\hline \multicolumn{2}{|l|}{ Abstract } \\
\hline Purpose: & $\begin{array}{l}\text { The purpose of this study was to examine the effect of exercise in the communication skills and behavior of a } \\
\text { child with Autistic Spectrum Disorder (ASD). }\end{array}$ \\
\hline Material: & $\begin{array}{l}\text { The survey involved a } 7 \text { years old boy attending a mainstream school who was diagnosed at } 2.5 \text { years of } \\
\text { age with pervasive developmental disorder and at } 3.5 \text { years of age with ADS. The annual re-assessment, at } \\
\text { the age of } 6 \text { defined him as a child with high functional autism. The study consisted of three phases. In the } \\
\text { interview process through a questionnaire, data concerning the overall picture of the boy was collected. The } \\
\text { same questionnaire was answered by all participants (parents, general class teacher, parallel support teacher } \\
\text { and physical education teacher) two days prior and two days after the implementation of the intervention } \\
\text { program, so as to record observations. The questionnaire investigated four areas, that is, intention or function } \\
\text { of communication, semantic categories and use of words, context (framework) communication and ways } \\
\text { (means) of communication. The intervention program lasted } 12 \text { weeks, at a frequency of } 3 \text { sessions per } \\
\text { week, of } 40-45 \text { minutes each session including balance activities, self-awareness exercises, group games (3-4 } \\
\text { people), visual - motor coordination activities, lateral movement and time and space orientation games. }\end{array}$ \\
\hline Results: & $\begin{array}{l}\text { After the implementation of the intervention program, the child showed significant improvement in all } \\
\text { domains and in almost all subcategories. }\end{array}$ \\
\hline Concl & $\begin{array}{l}\text { An individually structured exercise program results in a significant improvement in behavior, skills and } \\
\text { communication for a child with ASD. }\end{array}$ \\
\hline & nnaire, autism, neurodevelopmental \\
\hline
\end{tabular}

\section{Introduction}

Autism spectrum disorders (ASD) are complex, lifelong, neurodevelopmental conditions largely unknown, characterized by deficits in social reciprocity and communication, as well as by unusual, limited and recurrent behaviors that affect the child's social skills, communication and behavior [1].

ASDs appear in childhood and early childhood, causing delays in many key areas of development, such as learning speech, playing and interaction with others. Signs and symptoms of autism vary widely, as well as its effects. Some autistic children face only mild problems, while others have more barriers to overcome. Nevertheless, every child in autistic spectrum disorders experiences problems at least to some extent, in the areas of verbal and non-verbal communication, interpersonal relations and flexible thinking and behavior [2].

Exercise for children with autism, is a unique challenge and an integral part of fostering development, promote physical health and combat the manifestations of the disorder, since many children with ASD exhibit motor imbalances that affect body posture and performance of gross motor abilities such as walking, running, jumping, climbing, pushing and pulling. Motor deficits and imbalances occurring in childhood continue to persist in the later stages of life [3] since few intervention programs that focus on the long-term effect of exercise on children,

(c) Stavrou K., Tsimaras V., Alevriadou A., Gregoriadis A. , 2018 doi:10.15561/18189172.2018.0206 adolescents and adults with autism do exist.

The social and behavioral effects of autism are caused by inefficient sensory processing, which is manifested by problems in attention, behavior, learning, speech development, movement and coordination. Szot [4], examining the effect of exercise on improving static and dynamic balance of children with autism reported an improvement of $47.9 \%$ of this motor skill of great developmental importance, following the implementation of a 3 months' intervention program. As Szot [4] concluded, as the intensity and repetition of exercise during childhood increases over time, positive changes in child's movement and behavior are also noted.

Self-stimulating stereotyped behaviors are a defining feature of autism, maintained by inadequate sensory feedback exhibited by children with ASD. Ospina et al. [5] study found that the participation of children with autism in a low intensity program as this is determined by heart rate during exercise, decreases stereotyped and nonfunctional behaviors by $17.5 \%$. Fedak [6] study also showed that a program of intense physical activity was effective in reducing stereotypic behaviors in 23 children with ADS aged 5-13 years. Lang et al. [7] study observed a decrease in stereotyping, aggression, and problematic behavior in 64 individuals with ADS as a result of their participation in exercise, indicating also that fatigue was not the likely cause of diminishing maladaptive behaviors. Hence, it appears that exercise is responsible for reducing self-stimulating behaviors and especially intense aerobic 
activity can be used to control non-functional behaviors associated with autism improving in this way the overall functionality level of these individuals in everyday life [5]. Nevertheless, a recent study [8] concerning exercise for children with ADS, reported that participation in aerobic activities did not stereotyped behaviors.

Exercise that stimulates movement and deepens social communication can also be used as a treatment for improving social skills. In this regard, the use of creative dance as a treatment for children with autism is based on the possibility of social feedback produced. Mason [9] compared social skills of children with ASD with and without speech ability during a creative dance program, showing that both groups and especially children with no speech ability have benefited from this program, showing that creative dance eliminates social pressure of children with ASDs due to their interaction with peers.

Therapeutic riding is also an activity that provides benefits ranging from the therapeutic effects of the repeated gait movement to the gradual social interaction of the rider. In general, this form of exercise is particularly beneficial to children with autism allowing each child to interact with the horse and others without the worries caused by social and communicative deficits [9]. A similar later study [10] showed that a combined exercise program with therapeutic riding caused a significant reduction in stereotyped behavior in children with severe autism. Sowa \& Meulenbroek [11] study, assessing social and motor disorders in 133 children with ADS also reported significant benefits in terms of movement and social skills following their participation in physical activities.

Swimming also offers significant benefits to children with ASD. Yilmaz et al. [12], reported significant gains in balance, speed and agility skills, as well as in muscle strength, flexibility and endurance following a ten weeks' swimming program with increased intensity. Water orientation improvement was also highly related with a significant reduction in self-stimulating stereotypic behaviors, whereas children participating in the swimming program exhibited a more self-confident and self-awareness behavior following a water adaptation period. As Yilmaz et al. [12] stated, water exercise does not only benefit cardiovascular capacity of children with autism, but it is also believed to help in linguistic development as well as in self-perception and adaptive behavior improvement particularly during the early intervention period.

Reviewing the literature, it seems that swimming, creative dance, jogging and horse riding are effective forms of treatment for children with ASD. Nevertheless, in view of the fact that modern research literature has focused mainly on the relationship of psychomotor therapy to autism, the purpose of this study was to identify the degree of correlation between psychomotor treatment through exercise with behavioral modification. The main issue was to answer whether indirect contact or lack of social contact of children with ADS with their peers, relatives and friends without ADS can be improved through exercise in the form of psychomotor education.
In this regard, a detailed analytic inventory of behavior of the participant prior and after intervention was attempted.

\section{Material and Methods}

Participant

This study aimed to provide educational intervention to a 7-year-old boy who was diagnosed at 2.5 years of age with pervasive developmental disorder and at 3.5 years of age with ADS. The annual re-assessment, at the age of 6 defined him as a child with high functional autism. During the study, he attended a public primary school in the first grade and was supported by a parallel private personel (special education teacher). The boy had normal physical development according to his age, he was calm as a character with his own opinion and he was social with people he knew and wished their friendship, even with unfamiliar people who looked friendly. Otherwise, he kept his distance, feeling uncomfortable with social interaction. He had the tendency to play alone although he wanted at the same time to get in touch with other peers. His reaction depended on their reactions displaying eye contact except when reacting reluctantly.

\section{Procedure}

In this study, the following training tools were used to evaluate the participant.

1) The Childhood Autism Rating Scale (CARS) is a diagnostic tool designed to evaluate children at risk of developing ADS and determine the degree of autism among respondents. Appropriate for the assessment of children aged two years and older, CARS examine and rates a number of factors that can help distinguish children with ADS from those with other developmental disorders. In the form of a questionnaire, this scale is based on the direct observation of behavior by a practitioner, as well as reports from parents, teachers or children supervised by the child [13].

2) The Psycho-Educational Profile (PEP-R) [14], an instrument that assesses skills, behaviors and the developmental level of children with autism and other related disorders, useful to design their individualized educational programming [15].

3) A questionnaire used in the previous study [10], in which all respondents, that is, the parents of the child, the physical education (PE) teacher, the primary school (PS) teacher and the parallel support (personnel) teacher were asked to respond prior and after intervention. The interview questionnaire is a valid assessment tool that gathers data concerning the overall children's profile of strengths and weaknesses through questions that assesses emotional and behavioral issues and explores four areas of communication related to its means, function, framework, and semantic categories and use of words. All respondents replied to the same questionnaire two days before and two days after the intervention program.

Intervention program

The total duration of the intervention program was 12 
weeks, at a frequency of 3 sessions per week of 40-45 minutes each time. Each session started with a 7-minute warm-up, followed by the main part of the intervention program including balance activities, self-awareness exercises, group games (3-4 people), visual - motor coordination activities, lateral movement and time and space orientation games. A 1-2 minutes break interfered in every 10 minutes of exercise. Each session was completed with a 5-minute cool down period of walking around the basketball court line.

\section{Statistical analysis}

A qualitative research approach [1] was used for the analysis and processing of data, as it is effective in collecting information related to social behaviors, personal opinions and emphasizing data collection through questions and interventions that have not predecided.

\section{Results}

Results for behavior and each of the four areas of communication (function, semantic categories and use of words, framework and means) as recorded by the four respondents (parents, physical education (PE) teacher, primary school (PS) teacher and the parallel support personnel) prior and after intervention are presented in following figures.

Regarding 'intention or function' of communication changes were observed after intervention in "General" and "Asks" according to the PS teacher and parallel support personnel, in "Draws attention" and "Requires information" according to parents and "provides information according to the PE teacher. No changes were observed in all other factors (Figure 1).

Regarding "semantic categories and use of words", post intervention changes were observed in "General" according to parents, PS teacher and parallel support personnel, in "Objects" according to parallel support personnel, in "Individuals", "Actions" and "Internal condition" according to parents' opinion and "Quality" according to parents and the PE teacher. No other changes were observed in the two remained factors (Figure 2).

In relation to the Communication Framework following the implementation of the exercise program, changes in behavior were observed in questions 1 and 8 according to parents, in question 2 according to parents, PS teacher and PE teacher, in questions 3, 4 and 5 according to all 4 respondents in questions $6,9,10,11$ and 12 according to 3 out of 4 respondents except the PS teacher and in questions 7 and 13 as answered by the parallel support personnel (Figure 3).

As for communication means, behavior changes were observed following intervention in questions 1 (Kinetic/ objects) and 8 (Clarity) as reported by all 4 respondents in questions 2 (Gestures) and 5 (Written words) according to parents, PS teachers and PE teacher, in question 3 by parents and parallel support personnel, in question 6 (Speech) by parents and PS. No changes were noted in questions 4 and 7 (Figure 4).

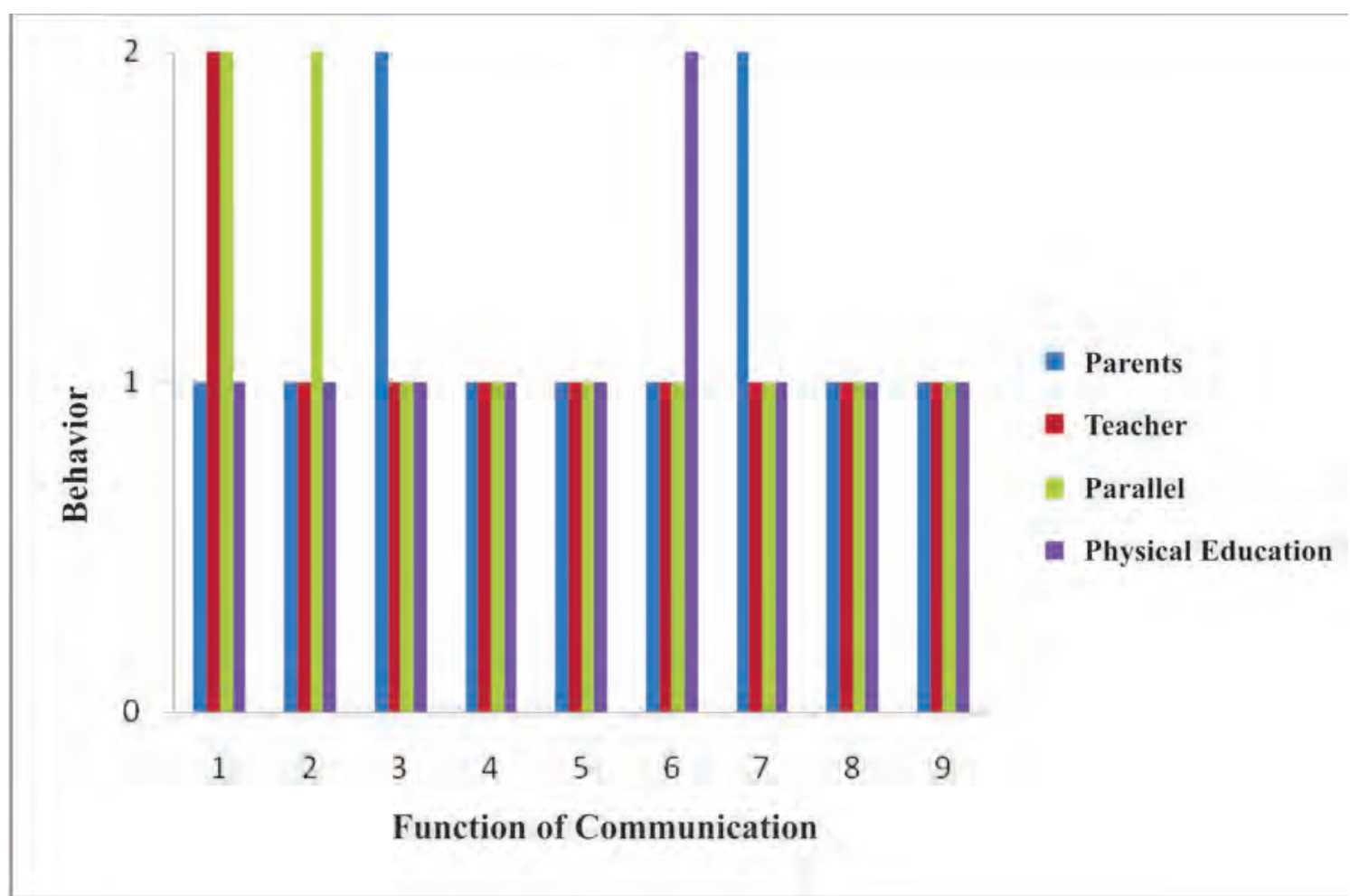

Figure 1. Intention or Function of Communication

Behavior: 1: No Change, 2: Change

Intention or Function of Communication: 1: General 2: Asks, 3: Draws attention, 4: Comments, 5: Refuses, 6: Provides information, 7: Requires information 8: Expresses emotions 9: Social routine 


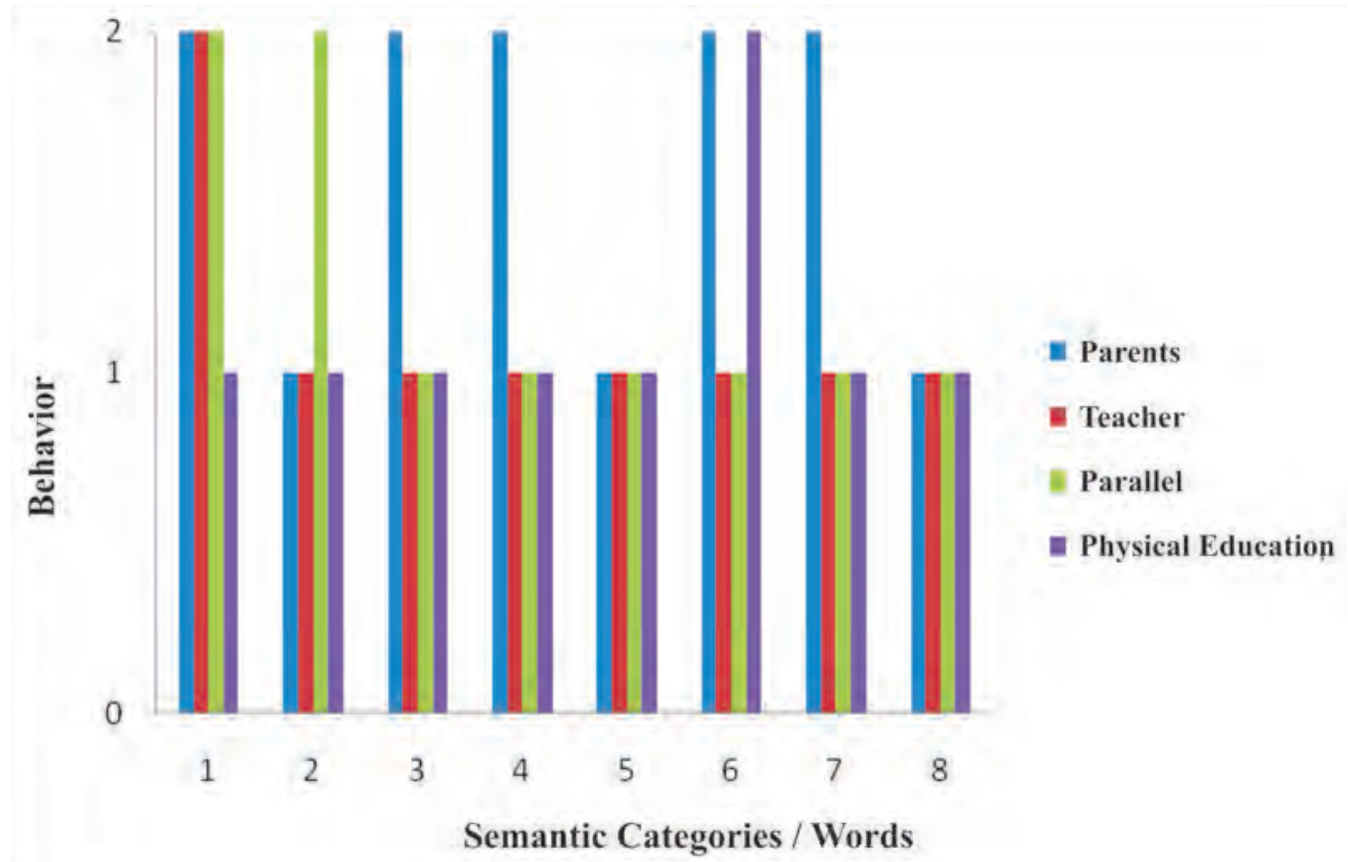

Figure 2. Semantic Categories and Use of words

Behavior: 1: No Change, 2: Change

Semantic Categories / Use of Words: 1: General, 2: Objects, 3: Individuals, 4: Actions, 5: Spaces, 6: Quality, 7: Internal condition, 8. Other.

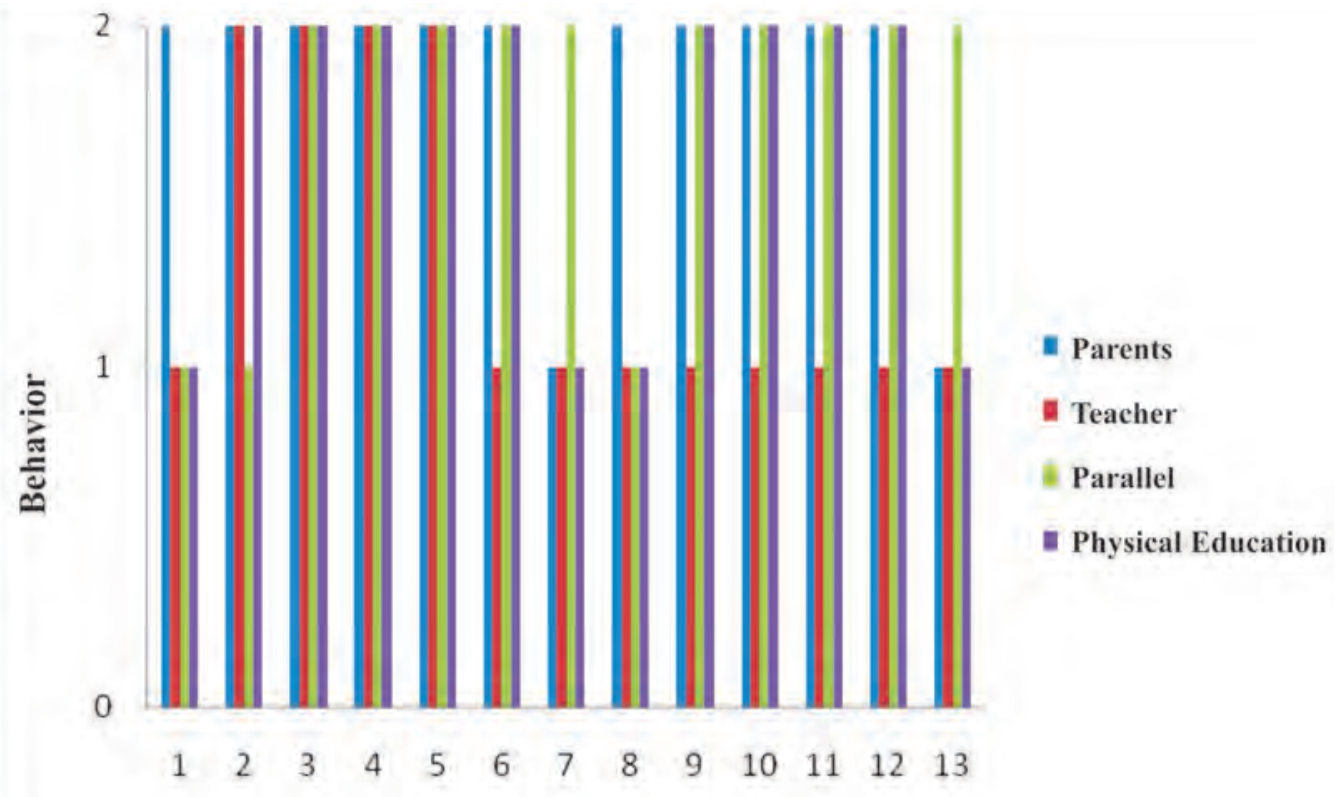

Communication Framework

Figure 3. Communication Framework

Behavior: 1: No Change, 2: Change

Communication Framework: 1. General: With whom the child is most trying to communicate with? Under which circumstances does he/she usually communicate more? 2. Does the child communicate better with you (the parents)? 3. Does the child communicate better with his/her brother(s) or sister(s)? 4. How about child's communication with his/her peers or other youngsters? 5. Does the child communicate with family friends and relatives? 6 . Does the child communicate easily with unknown persons? 7. Does the child usually communicate during lunch time? 8 . Does he communicate about housework that he can do? 9. Does he communicate for actions such as dressing, washing, brushing teeth etc? 10. Does he initiate communicate with you when you let him play on his own? 11 . When you go out together there are some activities you do or some places you go to which it is highly likely for him to communicate? 12. Are there other situations where you have noticed that he is highly communicative? 13 . Are there other situations in which you noticed that he is highly non-communicating or where communication is particularly inappropriate? 


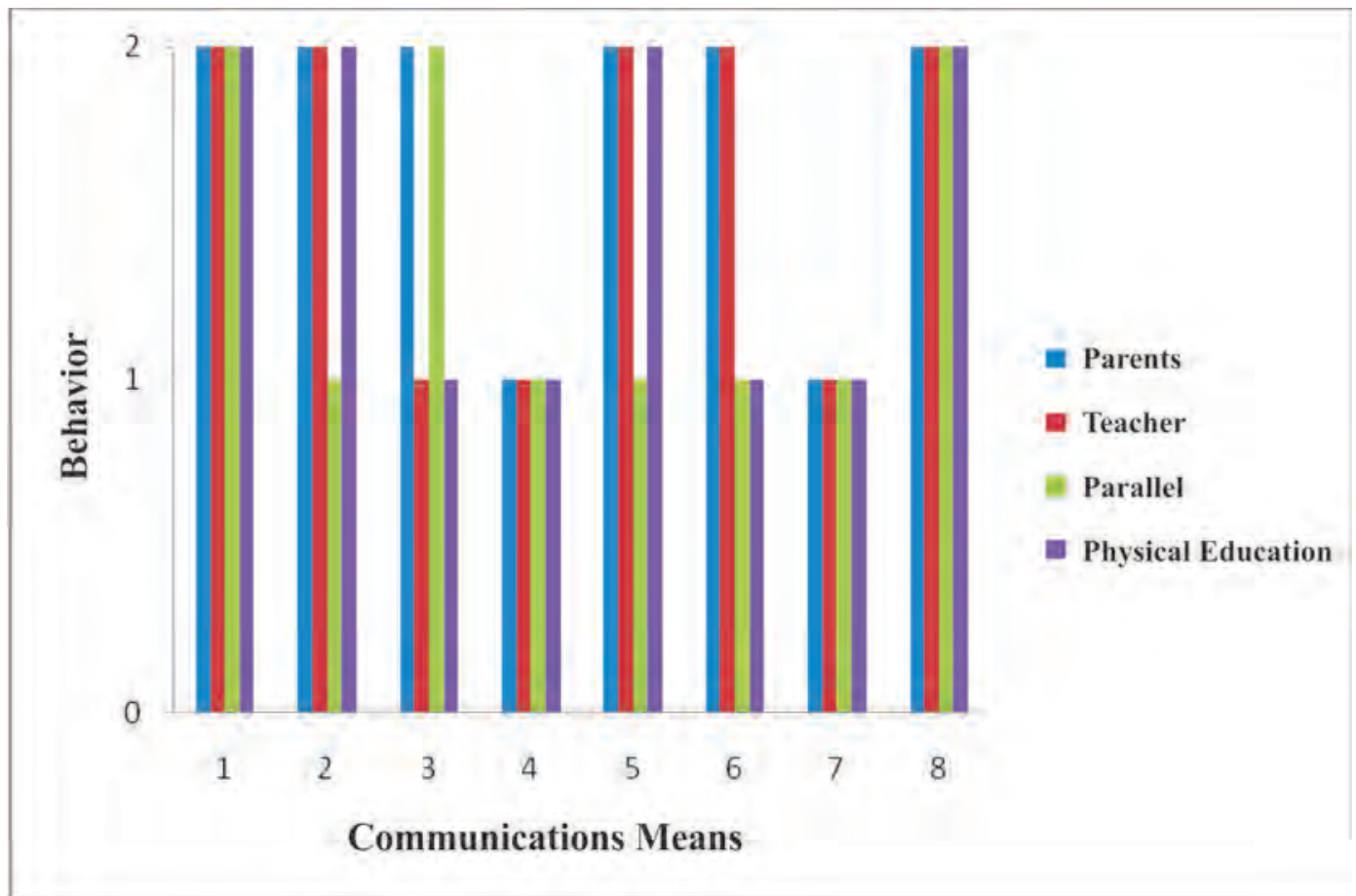

Figure 4. Communication Means

Behavior: 1: No Change, 2: Change

Communication Means: 1: Motor/objects, 2: Gestures, 3: Pictures, 4: Symbols, 5: Written words, 6: Speech, 7: Other, 8: Clarity.

\section{Discussion}

The purpose of this study was to investigate whether a psychomotor training program in the form of exercise is capable of bringing about positive changes in communication and behavior skills of a child with ADS.

In intention - function of communication the child following intervention showed a significant change according to all four respondents in most factors. In providing information, the positive change was equally significant and evident for the PS teacher and the parallel support personnel, except parents who saw little progress and the PE teacher who did not notice any progress at all. In commenting, the PS teacher reported little improvement, while the other three respondents perceived improvement as great. Finally, the boy continued not to ask for help from the PS teacher, in contrast with the other three respondents.

As for semantic categories and use of words, the PS teacher noticed no improvement in 'objects' and 'actions', while the parents reported little progress concerning internal condition (emotions). In all other categories a significant improvement was noticed by all respondents.

No change has been noted in communication framework during food and homework with the child continuing not to communicate. Furthermore, the classroom teacher did not notice any improvement in communication with non-familiar individuals contrast with all other respondents. In all other communication features, significant progress has been made.

In terms of the means that the child uses to communicate, the most significant and evident improvement was recorded by all respondents in all motoe, gesture, written words speech and clarity features, with the boy no longer using images and symbols anymore.

In summary, the findings of this study point out that the child completely stopped using images and symbols to communicate and began to use speech. The fact that he made himself understood by others in almost all of his speech efforts helped him to stop using PECS. Also, it is important to note that no deterioration was noticed in any trait measured, since only a few remained the same.

With regard to the research questions initially set, the answer to the first issue on whether there was a positive change noted in child's behavior following the psychomotor program is yes as the boy significantly improved his behavior in all trait areas measured. As for the second assumption on whether improvement could be evident in all three areas of child's activity, the outcome is positive in most behavior features but not all, especially according to the PS teacher point of view. Therefore, the main hypothesis of the child expected to show a marked improvement in all areas of behavior and relative skills after the intervention program is verified for most features, with the footnote that in some behavior and communication traits on differ settings, progress was not apparent.

The finding is in agreement with the study of GarciaVillamisar and Dattilo [8], who concluded that exercise for children with ADS helps them to cope with the manifestations of the disorder. Similar findings were also verified by the study of Filiou [1] stating that the most effective interventions for children with autism are those involving movement as in this study. Other researchers also reported that through exercise, positive behavior and 
motor changes are noted in children with ADS leading to a reduction of non-functional manners $[6,8,17,18]$. Szot [19] stated that exercises of high intensity are needed to achieve the desired behavior outcome, and unfortunately, the most well-known and widespread methods of treatment through movement for children with ADS do not focus on this area. His exercise program was based on repeating the exercises that incorporate duration, strength and frequency all together. Since repetition of exercises at a fixed duration often encountered the reluctance and often the refusal to perform, he also used a therapist or guardian who provided immediate help at any stage of the exercise program so as to reinforce positive outcomes. Following 4 years of scientific observation, a positive correlation was evident between repetition and alternation of exercises with positive changes in child's behavior. Similar results of positive correlation between exercise and behavior change although the relation of the exercise intensity and better outcomes was not measured.

Even in earlier research efforts [20], the usefulness of physical activity was demonstrated as a possible method of reducing self-stimulation behaviors. In seven children who had very high levels of self-stimulation, postintervention findings showed that exercise reduced selfstimulation and increased play and academic performance behavior. Positive behavior changes were evident in three different research environments regarding their academic performance (kindergarten skills), during ball games; and in the quiet room where no other activity took place. Measurements in a classroom environment during school also exhibited similar results.

In another earlier study [21], five boys with ADS who participated in three different programs, that is, exercise, TV watching and simple academic work, showed lower levels of self-stimulation after exercise, and no differences or decreases in self-stimulation levels after watching TV or doing simple academic work. Nevertheless, their performance in formulating correct answers to questions related to their socialization and communication was not affected by any of the three different programs preceded and did not differ in relation to the level at which they were prior the start of research inquiry. The latter finding is in contradiction with the findings of the present study as the participant showed an increase in his social and communicative skills through exercise. This difference is due to the fact that autism in each child is different and therefore a wise choice of following an individualized approach prior intervention is needed.

Kern et al. [22] examined the effect of light exercise on stereotypical behavioral patterns of three children aged 7-11 who participated in two exercise outdoor programs (jogging and relaxed ball games) of 15 minutes duration each. Following light exercise, no significant results of little or no effect on their stereotypic behavior were produced concerning the behavior of children, while continuous and intense exercise caused a significant reduction in stereotypic behaviors. The first finding is inconsistent with the findings of the present study since the child showed a significant reduction in stereotyped behaviors after exercise of low intensity. However, PEP-R and CARS diagnostic tools either were not available at that time or they were modified and upgraded later on to compare the contradictory results between the two studies.

Schurrer et al. [23] studied the behavior of five individuals with ADS who participated in an aerobic exercise program and recorded a performance increase in social activities and a reduction of aggressive and disruptive behavior of these individuals. Stahmer \& Schreibman [24] applied an exercise program through play activities to 3 children with ADS exhibiting persistent problematic selfstimulation behavior (hand hitting, toy spinning, etc.) and oobserved that self-stimulation behaviors were reduced as the intensity of playing increased.

Lang et al. [7], reviewing 18 previous researches and also implementing a study involving 64 individuals with ADS aged 3-41 years concluded that participants with ADS improve their behavior by incorporating regular and specific forms of physical activity, a finding that is in agreement with the findings of our study.

Axarli [10] reported that a combined exercise program of physical education activities and therapeutic riding improved the communication of 5 autistic children with their parents and teachers, a finding identical to the findings of this study. As Axarli [10] concluded, it is now generally accepted that autism in each child is manifested in a different way, thus, future intervention programs should be individualized.

\section{Conclusions}

The findings of the present study show that adapted physical education seemed effective in reducing stereotypical behavior of the child and developing his motor, social and communicative skills. Exercise has greatly improved communication skills of the child with autism, something that has reinforced collaboration with parents, teachers and team of experts. Improvement was evident in all three environments at home, school and outdoors. No deterioration was observed in any communication traits apart from some features remaining the same whereas most communication skills were improved. Furthermore, the psychomotor program seemed to be pleasant and acceptable to the child with ADS, enabling him to participate in socially acceptable motor activities.

An important role played the preparation of the child with ADS by all respondents and the way that this was done by each respondent so as to positively influence the psychology of the child, reduce his anxiety, increase self-confidence and consequently maximize the overall potential to improve performance and behavior. The effort of the parallel support personnel to integrate the child within different environments and the role of the PE teacher to select proper exercises that foster selfconfidence and communication skills are also considered crucial.

The value of findings emerging after 12 weeks of thorough investigation has its limitations related to case study designs that cannot be generalized. Future researches 
should also use semi-structured interviews to further look into deeper thoughts and beliefs of all participants that cannot be examined only through questionnaire use. A combination of qualitative and quantitative approach using larger sample of children with ADS could help to further ascertain the effect of exercise on behavior and communication skills as well as other ADS traits that were not examined in this study.

\section{Acknowledgements}

We are grateful to the child with autism spectrum disorder for his participation in this study. Also, we are grateful to the parents of the child, the physical education teacher, the primary school teacher and the parallel support teacher for their participation in this study. Furthermore, we want to express our gratitude to the instructor for her cooperation and unfailing support during this research. We would also like to thank the entire laboratory staff for their hard work for the completion of this study.

\section{Concflict of interests}

The authors declare that thare is no conflict of interests.

\section{References}

1. American Psychiatric Association. Diagnostic and Statistical Manual of Mental Disorders DSM-IV-TR (Text Revision). Washington, D.C.: American Psychiatric Association; 2005.

2. Myers SM, Johnson CP. Management of children with autism spectrum disorders. Pediatrics. 2007; 120:1162-82.

3. Oriel KN, George CL, Peckus R, Semon A. The effects of aerobic exercise on academic engagement in young children with autism spectrum disorder. Pediatr Phys Ther. 2011; 23(2):187-93.

4. Szot Z. The Influence of Kinetic Exercises on the Static Balance of People with Autism. Res Yearbook. 2005; 11(1):45-48.

5. Ospina MB, Seida J, Clark B, Karkhaneh M, Hartling L, Tjosovold L, Vandermeer B, Smith V. Behavioural and Developmental Interventions for Autism Spectrum Disorder: A Clinical Systematic Review. US National Med. 2008; 3(11):82-94.

6. Fedak AT. The effects of physical activity on the stereotypic behaviors of children with ASD. Honors Thesis, USA: Texas State University-San Marcos; 2012.

7. Lang R, Koegel LK, Ashbaugh K, Regester A, Ence W, Smith W. Physical exercise and individuals with autism spectrum disorders: A systematic review. Res Autism Spectrum Dis. 2010; 4(4):565-76.

8. Bernard HR. Research Methods in Anthropology. Second Edition. London: Sage Publications. Department of Physical Therapy, Lebanon Valley College, Annville, Pennsylvania: USA; 2011.

9. Mason G. Effects of therapeutic riding in children with autism. [PhD thesis]. Capella University; 2005.

10.Axarli, G. The effect of exercise and the therapeutic riding on behavior of children with autism. [Master Thesis]. Thessaloniki: Aristotle University of Thessaloniki; 2009.

11.Sowa M, Meulenbroek R. Effects of physical exercise on Autism Spectrum Disorders: A meta-analysis. 2011. [cited 2017 Nov 10]. Available from: http://www.researchgate.net/ publication/257692135_Effects_of_physical_exercise_on_ Autism_Spectrm_Disorders_A_meta-analysis. 2011.

12.Yilmaz J, Yanardag M, Birkan B, Bumin G. Effects of Swimming Training on Physical Fitness and Water Orientation in Autism. Pediatr Inter. 2004; 46:624-26.
13.Risis S, Lord C, Gotham K, Corsello C, Chrysler C, Szatmari $\mathrm{P}$, et al. Combining information from multiple sources in the diagnosis of autism spectrum disorders. J Am Academy Child Adolescent Psychiatry. 2006; 45:1094-95.

14.Schopler E, Van Bourgondien ME, Wellman GJ, Love SR. Childhood Autism Rating Scale ( $2^{\text {nd }}$ Edition). Los Angeles: Western Psychological Services; 2010.

15.American Academy of Neurology. Practice parameter: Screening and diagnosis of autistic spectrum disorders. Neurology. 2005; 55(4):468-79.

16.García-Villamisar DA, Dattilo J. Effects of a leisure program on quality of life and stress of individuals with ASD. $J$ Intellect Dis Res. 2010; 54(7):611-19.

17.Bernard HR. The effects of aerobic exercise on academic engagement in young children with autism spectrum disorder. Pediatr Phys Ther. 1995; 23(2):187-93.

18.Filiou A. The teaching of writing and psychomotor education in kindergarten school children with intellectual disabilities. Views and perceptions of kindergarten school teachers. [Master Thesis]. Thessaloniki: Aristotle University of Thessaloniki; 2010.

19.Szot Z. The method of stimulated serial repetitions of gymnastic exercises in therapy of autistic children. J Autism Develop Dis. 1997; 27(3):341-42.

20.Kern L, Koegel Rl, Dyer K, Blew PA, Fenton LR. The effects of physical exercise on self-stimulation and appropriate responding in autistic children. J Autism Develop Dis. 1982; 12: 399-419.

21.Watters RG, Watters WE. Decreasing self-stimulatory behavior with physical exercise in a group of autistic boys. $J$ Autism Develop Dis. 1980; 10:379-87.

22.Kern L, Koegel RL, Dunlap G. The influence of vigorous versus mild exercise on autistic stereotyped behaviors. $J$ Autism Develop Dis. 1984; 14:57-67.

23.Schurrer R, Weltman A, Brammel H. Effects of physical training on cardiovascular fitness and behavior patterns of mentally retarted adults. Am J Ment Def. 1985; 90(2):167-69.

24.Stahmer AC, Schreibman L. Teaching children with autism appropriate play in unsupervised environments using a self management treatment package. Appl Behavior Anal. 1992; 25(2):447-59. 


\section{Information about the authors:}

Stavrou K.; MSc; http://orcid.org/0000-0001-8615-0541; kiriakis21@gmail.com; School of Early Childhood Education, University of Western Macedonia; 3o Km. National Road Florinas - Nikis, Florina, Greece.

Tsimaras V. (Corresponding author); PhD; http://orcid.org/0000-0003-3170-4417; tsimaras@phed.auth.gr; School of Physical Education and Sport Science, Aristotle University of Thessaloniki, New Building Facilities of the School of Physical Education and Sports Science, 57001 Thermi, Greece.

Alevriadou A.; PhD; http://orcid.org/0000-0001-7022-5537; alevriadou@uowm.gr; School of Early Childhood Education, University of Western Macedonia; 3o Km. National Road Florinas - Nikis, Florina, Greece.

Gregoriadis A.; PhD; http://orcid.org/0000-0002-3026-6614; asis@nured.auth.gr; School of Early Childhood Education, Aristotle University of Thessaloniki; Campus - Tower of Childhood Education Faculty, 541 24, Thessaloniki, Greece.

Cite this article as: Stavrou K, Tsimaras V, Alevriadou A, Gregoriadis A. The effect of an exercise program on communication and behavior of a child with Autism Spectrum Disorder. Pedagogics, psychology, medical-biological problems of physical training and sports, 2018;22(2):99-106. doi:10.15561/18189172.2018.0206

The electronic version of this article is the complete one and can be found online at: http://www.sportpedagogy.org.ua/index.php/PPS/issue/archive

This is an Open Access article distributed under the terms of the Creative Commons Attribution License, which permits unrestricted use, distribution, and reproduction in any medium, provided the original work is properly cited (http://creativecommons.org/licenses/by/4.0/deed.en).

Received: 19.11.2017

Accepted: 08.12.2017; Published: 30.04.2018 